\title{
Potential of biomarkers during pharmacological therapy setting for postmenopausal osteoporosis: a systematic review
}

Filippo Migliorini ${ }^{1 *}$ (D, Nicola Maffulli ${ }^{2,3,4}$, Filippo Spiezia ${ }^{5}$, Giuseppe Maria Peretti ${ }^{6,7}$, Markus Tingart ${ }^{1}$ and Riccardo Giorgino ${ }^{7}$

\begin{abstract}
Background: Biochemical markers of bone turnover (BTMs), such as the bone alkaline phosphatase (bALP), procollagen type I N propeptide (PINP), serum cross-linked C-telopeptides of type I collagen (bCTx), and urinary cross-linked N-telopeptides of type I collagen (NTx), are used to manage therapy monitoring in osteoporotic patients. This systematic review analyzed the potential of these BMTs in predicting the clinical outcomes in terms of $\mathrm{BMD}$, t-score, rate of fractures, and adverse events during the therapy setting in postmenopausal osteoporosis.

Methods: All randomized clinical trials (RCTs) reporting data on biomarkers for postmenopausal osteoporosis were accessed. Only articles reporting quantitative data on the level of biomarkers at baseline and on the outcomes of interest at the last follow-up were eligible.

Results: A total of 36,706 patients were retrieved. Greater values of bALP were associated with a greater rate of vertebral $(P=0.001)$ and non-vertebral fractures $(P=0.0001)$. Greater values of NTx at baseline were associated with a greater rate of adverse events at the last follow-up $(P=0.02)$. Greater values of $C T x$ at baseline were associated with a greater rate of adverse events leading to discontinuation $(P=0.04)$, gastrointestinal adverse events $(P=$ 0.0001), musculoskeletal adverse events $(P=0.04)$, and mortality $(P=0.04)$. Greater values of PINP at baseline were associated with greater rates of gastrointestinal adverse events $(P=0.02)$ at the last follow-up.
\end{abstract}

Conclusion: The present analysis supports the adoption of BMTs during pharmacological therapy setting of patients suffering from osteoporosis.

Level of evidence: I, systematic review of RCTs

Keywords: Osteoporosis, Biomarkers, bALP, PINP, bCTx, NTx

\section{Introduction}

The management of osteoporosis represents an important therapeutic challenge for the global health system and constitutes a considerable health expenditure [1-3].

\footnotetext{
*Correspondence: migliorini.md@gmail.com

${ }^{1}$ Department of Orthopaedic Surgery, University Clinic Aachen, RWTH Aachen University Clinic, Pauwelsstraße 30, 52074 Aachen, Germany Full list of author information is available at the end of the article
}

In addition, increasing in average age $[4,5]$ could have a significant impact on healthcare costs for the wide range of drugs that are used to manage osteoporotic patients [6-8]. Different drugs and administration methods have been shown to be more effective than others in the prevention of a certain complication or clinical outcomes such as BMD, $\mathrm{t}$-score, rate of fractures, and adverse events [9-14]. However, prevention of complication

(c) The Author(s). 2021 Open Access This article is licensed under a Creative Commons Attribution 4.0 International License, which permits use, sharing, adaptation, distribution and reproduction in any medium or format, as long as you give appropriate credit to the original author(s) and the source, provide a link to the Creative Commons licence, and indicate if changes were made. The images or other third party material in this article are included in the article's Creative Commons licence, unless indicated otherwise in a credit line to the material. If material is not included in the article's Creative Commons licence and your intended use is not permitted by statutory regulation or exceeds the permitted use, you will need to obtain permission directly from the copyright holder. To view a copy of this licence, visit http://creativecommons.org/licenses/by/4.0/ The Creative Commons Public Domain Dedication waiver (http://creativecommons.org/publicdomain/zero/1.0/) applies to the data made available in this article, unless otherwise stated in a credit line to the data. 
along the natural history of the disease is not an easy task to obtain $[15,16]$.

Biochemical markers of bone turnover (BTMs) have gained popularity for their ability to provide specific and dynamic indications of bone turnover mechanisms in the delicate balance between formation and resorption [17-19]. More precisely, serum bone alkaline phosphatase (bALP) and procollagen type I N propeptide (PINP) are considered biomarkers of bone ossification, while serum cross-linked C-telopeptides of type I collagen (bCTx) and urinary cross-linked $\mathrm{N}$-telopeptides of type I collagen (NTx) are considered indicators of bone resorption $[17,20,21]$. For their role in bone turnover, these BMTs could be used as a tool for monitoring therapy in osteoporosis [22-24]. With these assumptions, a systematic review has been performed to identify in these markers a predictor role for complications in the osteoporotic patient, and their ability to intervene with the most effective drug for the individual patient.

The purpose of the present study was to establish the potential of bALP, PINP, bCTx, and NTx in predicting the clinical outcomes in terms of BMD, t-score, rate of fractures, and adverse events during the therapy setting in patients with postmenopausal osteoporosis.

\section{Material and methods}

\section{Search strategy}

The present study followed the Preferred Reporting Items for Systematic Reviews and Meta-Analyses (PRIS MA) [25]. The PICOT framework was structured as follows:

- P (problem): postmenopausal osteoporosis

- I (intervention): bALP, PINP, bCTx, and NTx

- C (control): therapy setting

- O (outcomes): BMI, fractures, adverse events

- $\mathrm{T}$ (timing): $\geq 6$ months of follow-up

Two authors $(\mathrm{FM} ; \mathrm{RG})$ independently performed the literature search. In December 2020, the following databases were accessed: PubMed, Google Scholar, Embase, and Scopus. No time constraints were set for the database search. The following keywords were used in combination: osteoporosis, treatment, management, drug, pharmacology, pharmacological, medicament, mineral, density, bone, BMD, bone alkaline phosphatase, ALP, procollagen type I $N$ propeptide, PINP, serum crosslinked C-telopeptides of type I collagen, CTx, urinary cross-linked N-telopeptides of type I collagen, NTx, premenopausal, spine, pathological, fragility, fractures, hip, vertebral, disability, adverse events, Bisphosphonates, Denosumab, Romosozumab, Clodronate, Raloxifene, Teriparatide, Alendronate, Risedronate, Zoledronate, Ibandronate, Etidronate, PTH, osteoblast, osteoclast. The resulting articles were screened by the same authors. The full text of the articles of interest was accessed. A cross-reference of the bibliographies was also performed.

\section{Eligibility criteria}

All randomized clinical trials (RCTs) reporting data on biomarkers for postmenopausal osteoporosis were accessed. According to the authors' language capabilities, articles in English, French, German, Italian, Portuguese, and Spanish were eligible. Only studies of level I evidence, according to the Oxford Centre of EvidenceBased Medicine (OCEBM) [26] were considered. Articles reporting data on patients with secondary osteoporosis were excluded. Studies concerning patients with tumors and/or bone metastases were also not included. Studies reporting data on patients with iatrogenic-induced menopausal were not included, nor those on pediatric and/or adolescent patients. Studies regarding selected patients undergoing immunosuppressive therapies or organ transplantation were not considered. Studies reporting data on combined therapies with multiple drugs were not eligible. Studies with follow-up shorter than 6 months were not eligible, nor were those involving less than 10 patients. Studies reporting data of combined therapy with multiple anti-osteoporotic drugs were also not included. Only articles reporting quantitative data on the level of biomarkers at baseline and on the outcomes of interest were eligible. Missing data under these endpoints warranted the exclusion from the present work.

\section{Data extraction and outcomes of interests}

Two authors $(\mathrm{FM} ; \mathrm{RG})$ performed data extraction. Study generalities (author, year, journal, duration of the followup, daily calcium and vitamin D supplementation, treatment) and patient baseline demographic information were collected: number of samples, mean age, mean bone mass index (BMI), mean BMD (overall, spine, hip, femur neck), $t$ score (spine, hip, femur), and number of previous vertebral and non-vertebral fragility fractures. Data concerning the following endpoints were collected at the last follow-up: mean BMD (overall, spine, hip, femur neck), rate of vertebral, non-vertebral, femoral, hip fragility fractures, and body height. Data concerning the following adverse events at the last follow-up were collected: overall adverse events, serious adverse events and those leading to study discontinuation, gastrointestinal events, musculoskeletal events, rate of osteonecrosis, and mortality. Data concerning bALP, PINP, bCTx, and NTx were extracted at baseline and last follow-up. The outcomes of interest were to assess the association between biomarkers and patient characteristics, bone mass density, and adverse events at the last follow-up. 


\section{Methodological quality assessment}

The methodological quality assessment was made through the risk of bias graph tool of the Review Manager Software (The Nordic Cochrane Collaboration, Copenhagen). The following risks of bias were evaluated: selection, detection, performance, reporting, attrition, and other sources of bias.

\section{Statistical analysis}

The statistical analyses were performed by the main author (FM). The IBM SPSS software version 25 was used to assess data at baseline. Data distribution was evaluated using the Shapiro-Wilk test. Normally distributed data were evaluated using mean and standard deviation (SD), while median and interquartile range (IQR) were calculated for non-parametric data. The Student $T$-test was used to assess significance for parametric data, while the Mann-Whitney $U$-test for non-parametric variables.
Values of $\mathrm{P}<0.05$ are considered statistically significant. Multiple linear pairwise correlations were performed to assess associations between the value of the biomarkers at baseline and patient demographics, bone mass density, and adverse events at the last follow-up. The STATA Software/MP version 16 (StataCorporation, College Station, TX, USA) is used for the statistical analyses. A multiple linear model regression analysis through the Pearson product-moment correlation coefficient $(r)$ was used. The Cauchy-Schwarz formula was used for inequality: +1 is considered as positive linear correlation, while -1 a negative one. Values of $0.1<|r|<0.3,0.3<$ $|r|<0.5$, and $|r|>0.5$ were considered to have weak, moderate, and strong correlation, respectively. The overall significance was assessed through the $\chi^{2}$ test, with values of $\mathrm{P}<0.05$ considered statistically significant.

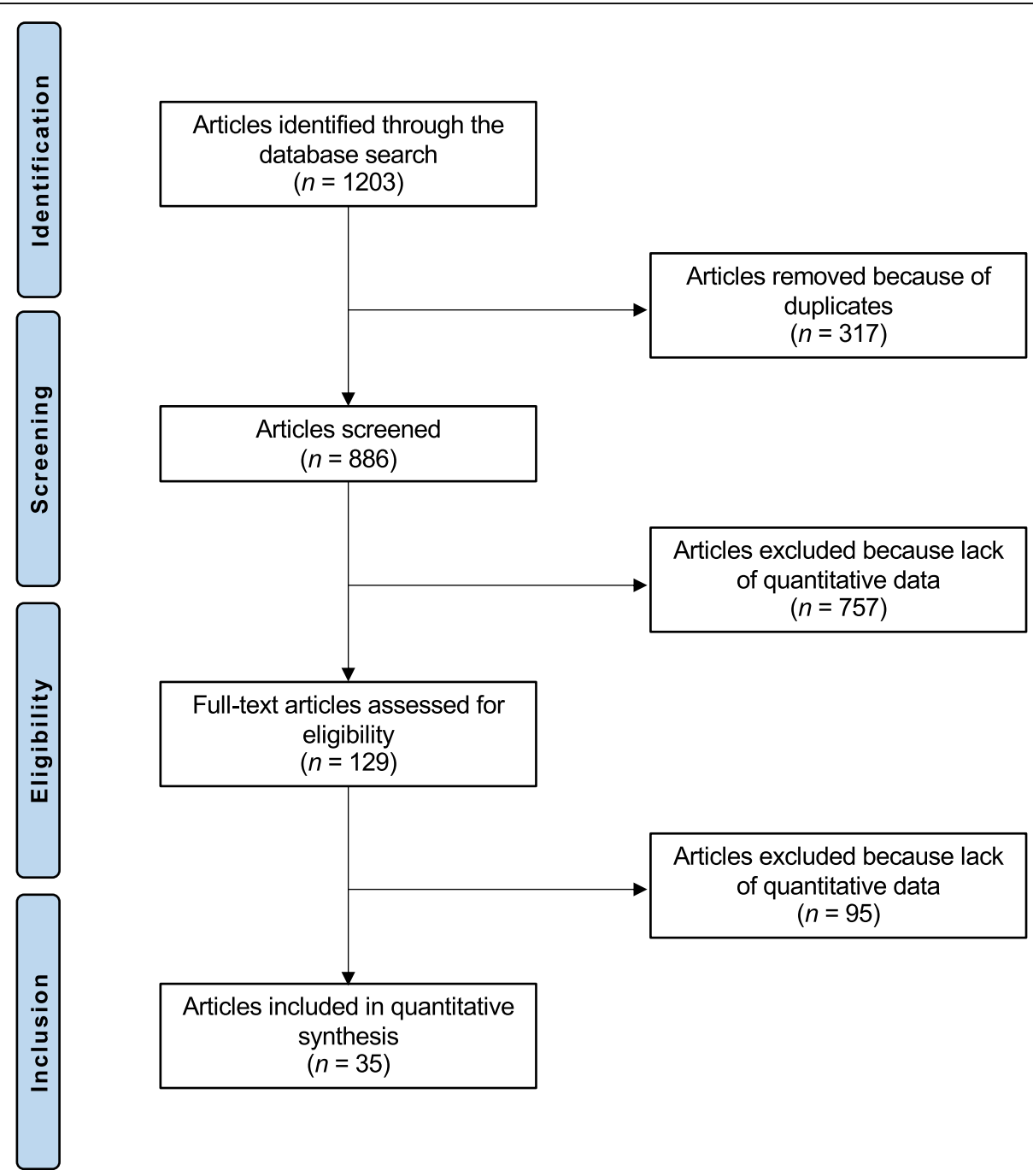

Fig. 1 Flow chart of the literature search 


\section{Results}

\section{Search result}

The literature search resulted in 1203 studies. Of them, 317 were duplicates. A further 757 articles were excluded because of study design $(\mathrm{N}=221)$, non-clinical studies $(\mathrm{N}=319)$, secondary osteoporosis $(\mathrm{N}=87)$, small population or short follow-up $(\mathrm{N}=15)$, multiple therapies $(\mathrm{N}=33)$, language limitations $(\mathrm{N}=5)$, uncertain results $(\mathrm{N}=11)$, and others $(\mathrm{N}=66)$. Another 95 articles were excluded because of data under the outcomes of interest missing. Finally, 35 RCTs were eligible for the present study (Fig. 1).

\section{Methodological quality assessment}

Given the exclusive inclusion of only RCTs, the risk of selection bias was low. Most of the studies were single and double blinded, leading to moderate-low risk of detection and performance biases. Overall, the high quality of the studies leads to a low risk of attrition and reporting bias. Concluding, the results of the review evaluation about each risk of bias item for each individual included study (Fig. 2) were low to moderate, leading to a good assessment of the methodology.

\section{Patient demographics}

A total of 36,706 patients were included. The median age was 67 (IQR 5), the median BMI 25.4 (IQR 1.9). The median vertebral BMD was 0.84 (IQR 0.17), hip BMD 0.74 (IQR 0.11), and femur BMD 0.64 (IQR 0.03). The ANOVA test found optimal within-group variance concerning age, BMI, and BMDs $(\mathrm{P}>0.1)$. Generalities and patient baseline data of the included studies are shown in detail in Table 1.

\section{Outcomes of interest}

Greater values of bALP results associated with a greater rate of vertebral fractures $(\mathrm{P}=0.001 ; r=0.8)$, nonvertebral fractures $(\mathrm{P}=0.0001 ; r=0.7)$, overall $\mathrm{BMD}(\mathrm{P}$ $=0.01 ; r=-0.8)$, BMD hip $(\mathrm{P}=0.04 ; r=-0.5)$, and BMD femur ( $\mathrm{P}=0.003 ; r=-0.9)$ at baseline. No association with bALP at baseline and other endpoints at follow-up was found. Greater values of NTx were associated with lower $\mathrm{T}$ score of the spine $(\mathrm{P}=0.03 ; r=-0.7)$ and of the hip ( $\mathrm{P}=0.04 ; r=-0.7)$ at baseline. Greater values of NTx at baseline were associated with a greater rate of adverse events at the last follow-up ( $\mathrm{P}=0.02 ; r=$ 0.9). Greater values of CTx were associated with lower BMD spine ( $\mathrm{P}=0.04 ; r=-0.3)$, $\mathrm{BMD}$ hip ( $\mathrm{P}=0.01 ; r=$ $0.5)$, and BMD femur ( $\mathrm{P}=0.0007 ; r=0.6)$ at baseline. Greater values of CTx at baseline were associated with a greater rate of adverse events leading to discontinuation $(\mathrm{P}=0.04 ; r=0.5)$, gastrointestinal adverse events $(\mathrm{P}=$ $0.0001 ; r=0.7)$, musculoskeletal adverse events $(\mathrm{P}=$ $0.04 ; r=0.4)$, and mortality $(\mathrm{P}=0.04 ; r=0.6)$. Greater values of PINP were associated with lower BMD at baseline $(\mathrm{P}=0.008 ; r=-0.4)$. Greater values of PINP at baseline were associated with a greater rate of gastrointestinal adverse events $(P=0.02 ; r=0.6)$ at the last follow-up. No further statistically significant associations were found. Table 2 shows the overall results of the multivariate analyses.

\section{Discussion}

According to the systematic review, all BMTs analyzed were useful to monitor the effects of pharmacological therapy setting in postmenopausal osteoporosis. Greater values of bALP have been associated with vertebral fractures and non-vertebral fractures with overall BMD, hip BMD, and femur BMD at baseline. Furthermore, greater

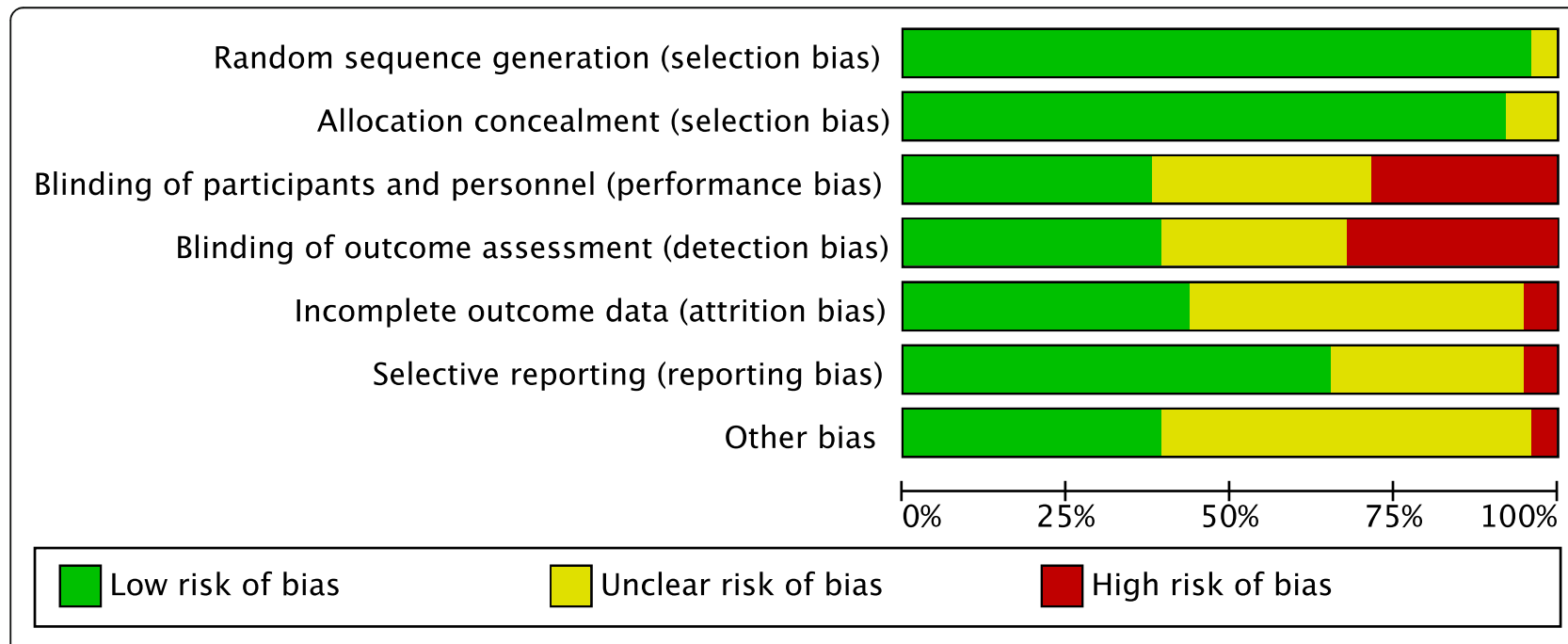

Fig. 2 Methodological quality assessment 


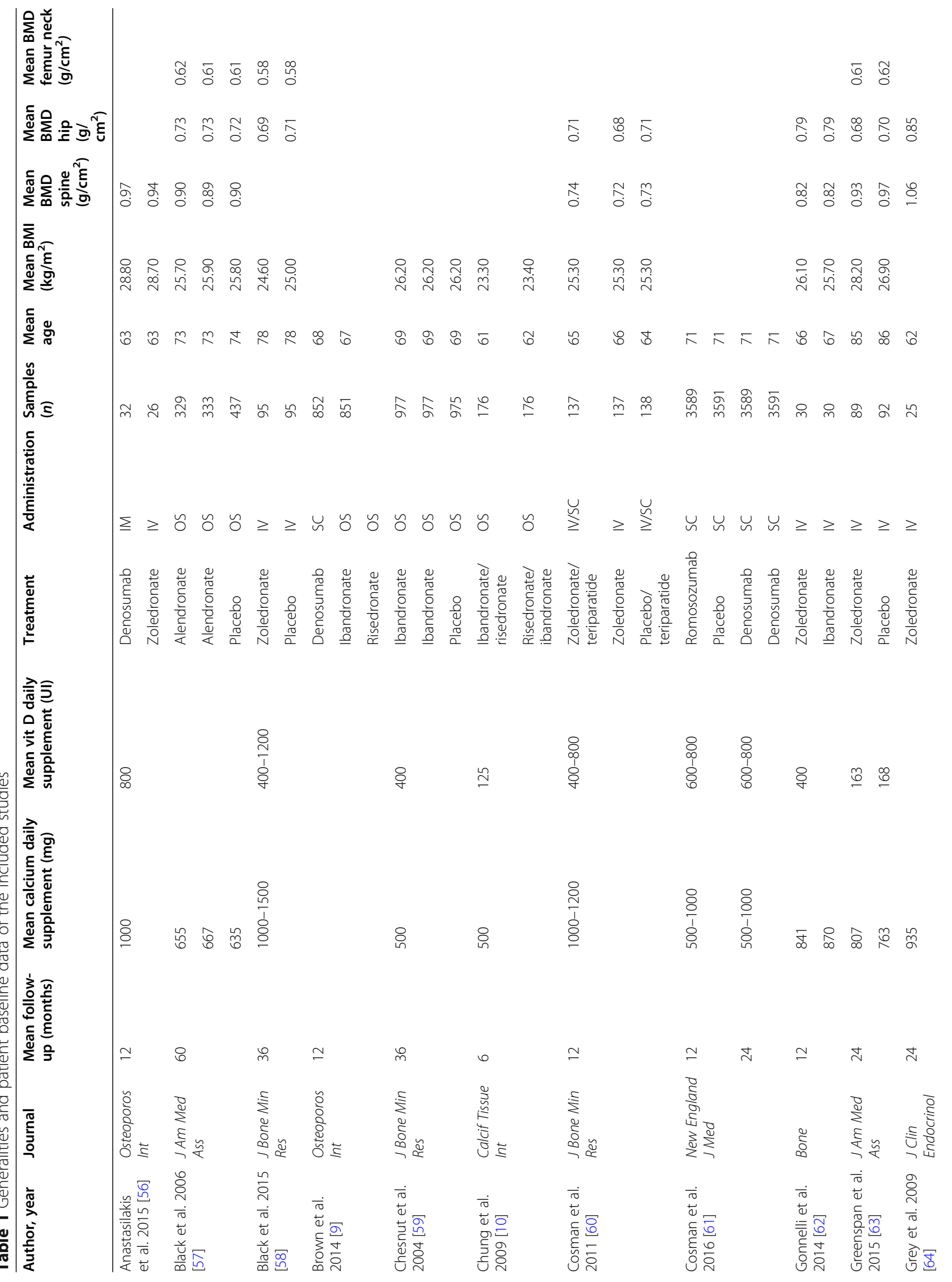




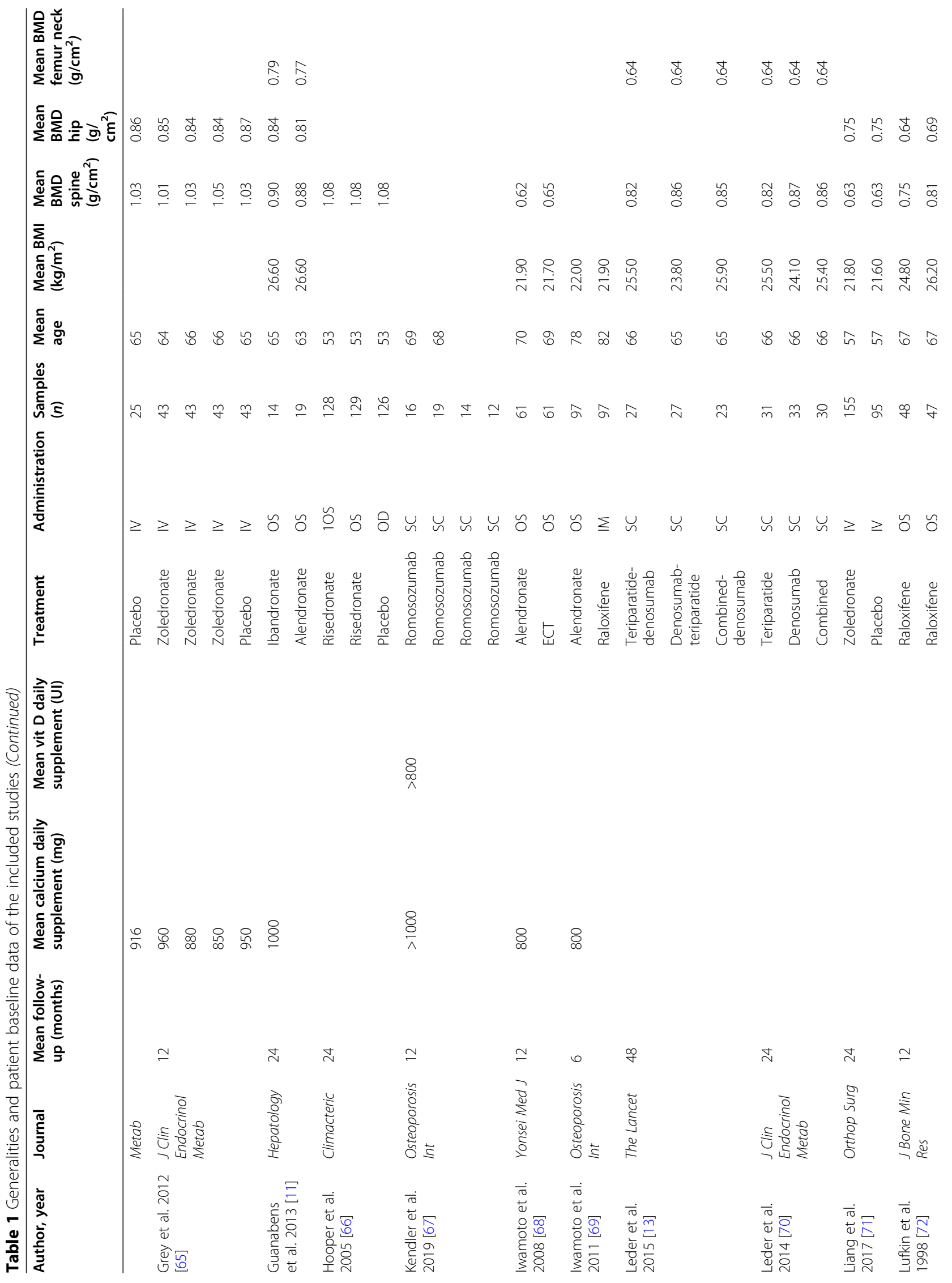




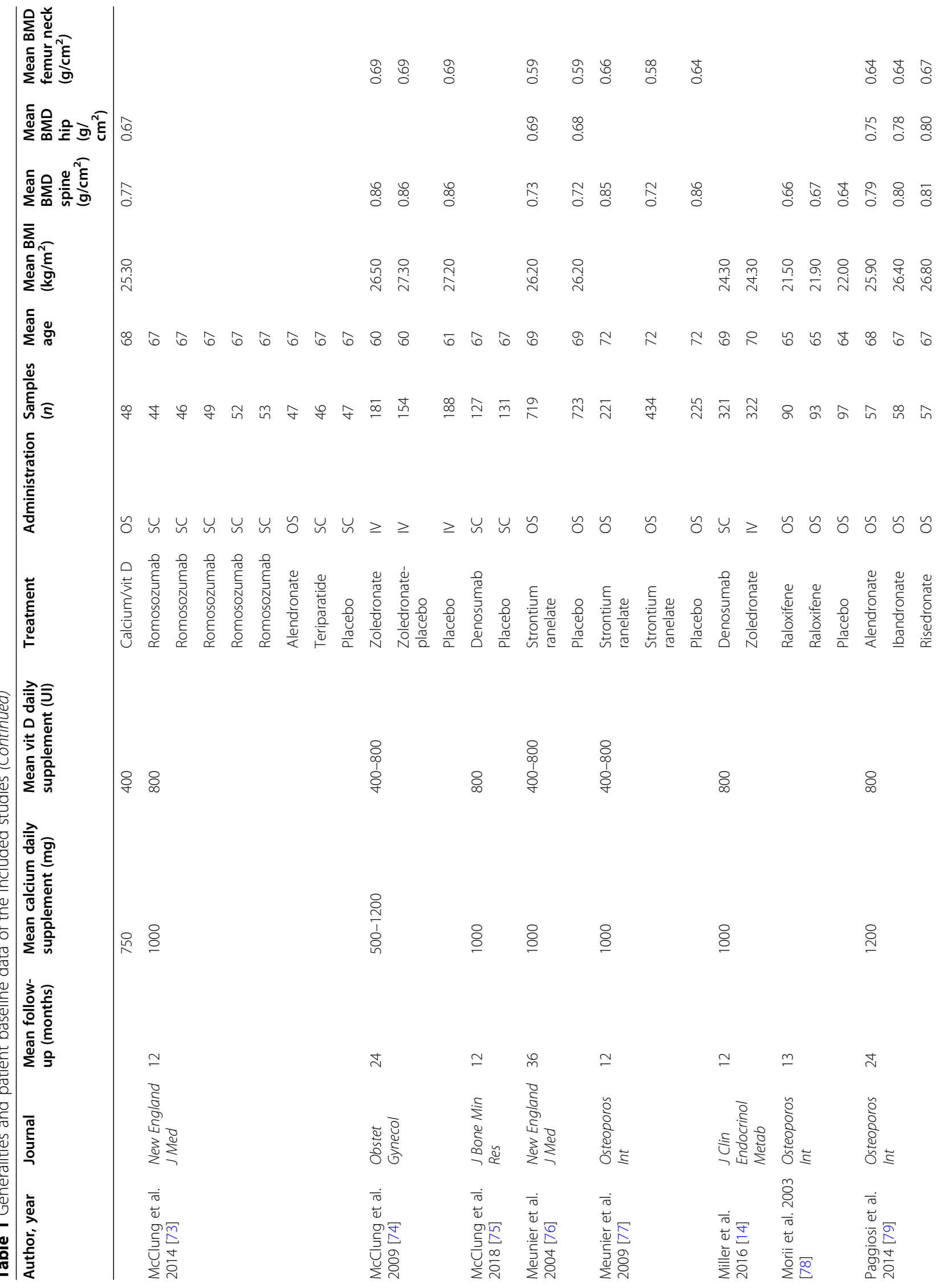




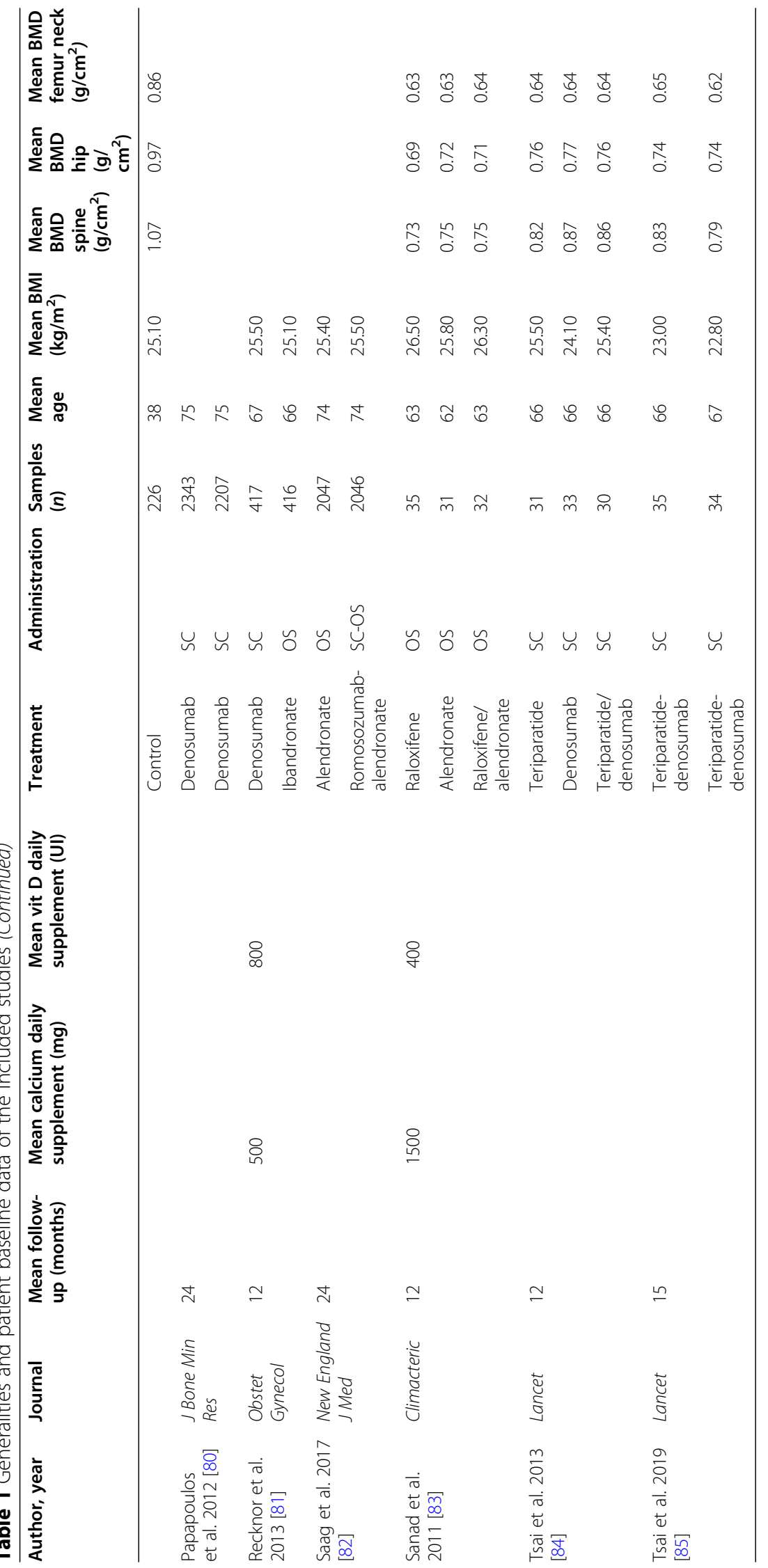


Table 2 Overall results of the pairwise correlations

\begin{tabular}{|c|c|c|c|c|c|c|c|c|}
\hline \multirow[t]{2}{*}{ Endpoint } & \multicolumn{2}{|l|}{ bALP } & \multirow{2}{*}{$\begin{array}{l}\text { NTX } \\
P\end{array}$} & \multicolumn{2}{|l|}{ CTx } & \multicolumn{3}{|l|}{ PINP } \\
\hline & $P$ & $r$ & & $r$ & $P$ & $r$ & $P$ & $r$ \\
\hline \multicolumn{9}{|l|}{ Baseline } \\
\hline Vertebral fractures & 0.0001 & 0.8 & 0.3 & 0.3 & 0.6 & 0.1 & 0.4 & 0.2 \\
\hline Non-vertebral fractures & 0.01 & 0.7 & 0.1 & 0.9 & 0.8 & -0.1 & 0.3 & 0.2 \\
\hline BMD & 0.01 & -0.8 & 0.5 & 0.4 & 0.1 & 0.5 & 0.008 & -0.4 \\
\hline BMI & 0.9 & 0.0 & 0.09 & -0.4 & 0.4 & -0.3 & 0.2 & -0.2 \\
\hline BMD spine & 0.2 & -0.3 & 0.6 & 0.2 & 0.04 & -0.3 & 0.5 & -0.1 \\
\hline BMD hip & 0.04 & -0.5 & 0.9 & -0.1 & 0.01 & 0.5 & 0.06 & 0.4 \\
\hline BMD femur & 0.003 & -0.9 & 0.2 & -0.5 & 0.0007 & 0.6 & 0.2 & 0.4 \\
\hline T score spine & 0.4 & -0.3 & 0.03 & -0.7 & 0.5 & -0.1 & 0.6 & 0.1 \\
\hline T score femur & 0.07 & 0.5 & 0.08 & -0.8 & 0.09 & 0.3 & 0.5 & 0.1 \\
\hline T score hip & 0.1 & 1.0 & 0.04 & -0.7 & 0.3 & 0.2 & 0.8 & 0.0 \\
\hline \multicolumn{9}{|l|}{ Follow-up } \\
\hline BMD spine & 0.9 & 0.0 & 0.4 & 0.3 & 0.4 & 0.1 & 0.3 & 0.2 \\
\hline BMD hip & 0.2 & 0.3 & 0.9 & 0.1 & 0.3 & 0.2 & 0.3 & 0.2 \\
\hline BMD femur & 0.3 & 0.3 & 0.9 & 0.0 & 0.3 & 0.4 & 0.3 & 0.3 \\
\hline Body height & 1.00 & -1.0 & 0.1 & -1.0 & 0.1 & 1.0 & 0.1 & 1.0 \\
\hline Non-vertebral fractures & 0.3 & -0.3 & 0.1 & 1.0 & 0.4 & -0.2 & 0.7 & -0.1 \\
\hline Vertebral fractures & 0.5 & -0.2 & 0.7 & -0.2 & 0.3 & -0.9 & 0.3 & 0.2 \\
\hline Hip fractures & 1.00 & 1.0 & & & 1.0 & -1.0 & & \\
\hline Femur fractures & 0.1 & -1.0 & & & 0.07 & -0.7 & 0.1 & -1.0 \\
\hline Adverse events & 0.9 & 0.0 & 0.02 & 0.9 & 0.1 & 0.2 & 0.9 & 0.0 \\
\hline Serious adverse events & 0.1 & -1.0 & 0.9 & 0.2 & 0.1 & 0.3 & 0.5 & 0.2 \\
\hline Adverse events leading to discontinuation & 0.1 & 0.6 & 0.3 & -0.4 & 0.04 & 0.5 & 0.4 & 0.2 \\
\hline Gastrointestinal adverse events & 0.3 & -0.6 & 0.3 & 0.3 & 0.0001 & 0.7 & 0.02 & 0.6 \\
\hline Musculoskeletal adverse events & 0.8 & -0.1 & & & 0.04 & 0.4 & 0.4 & 0.2 \\
\hline Osteonecrosis & & & & & 0.9 & -0.1 & 0.4 & -0.4 \\
\hline Mortality & 1.00 & 1.0 & 0.93 & 0.1 & 0.04 & 0.6 & 0.1 & 0.5 \\
\hline
\end{tabular}

values of NTx were associated with lower T score of the spine and of the hip at baseline. Greater values of NTx at baseline were also associated to adverse events at the last follow-up. CTx showed interesting associations, too: greater values were associated to lower spine, hip, and femur BMD at baseline. Greater values of this BMT at baseline were also associated to a greater rate of adverse events leading to discontinuation, gastrointestinal adverse events, musculoskeletal adverse events, and mortality. Finally, greater values of PINP were associated to lower BMD at baseline. High values at baseline have been associated to gastrointestinal adverse events at the last follow-up. Because of their ability to provide information about rapid changes in bone turnover, BMTs have been the subject of numerous studies to investigate their possible role in the management of osteoporotic patients $[17,18,27]$. Bone turnover is a dynamic process which involves bone resorption and bone formation [28,
29]. Several bone turnover markers have been highlighted in clinical practice [27, 30,31], although not to necessarily identify better therapy outcomes.

Markers of bone formation and resorption have been classified [17]. BALP and PINP are considered bone formation markers [32]. BALP is a membrane-bound enzyme produced by osteoblasts, positively correlated with bone formation $[17,33]$. Its role in identifying the risk of fracture has been highlighted [34] when Bjarnason et al. first demonstrated the relationship between the modification of the values of this BMT and the risk of fracture $[17,33]$. Statistically significant associations between bALP levels and fracture risk have been also analyzed showing possible association with numerous BMTs [35]. However, the association was not statistically significant, which was not the case for osteocalcin (OC), PINP, CTx, and NTx [35]. In a Japanese population, in contrast, bALP did predict vertebral fractures [36]. The 
association between bALP levels and BMD was instead analyzed in adults with and without diabetes [37]. In non-diabetic subjects, bALP levels were associated to BMD [37]. On the other hand, there was no relationship between bALP and BMD in elderly men with no history of fractures [38]. Procollagen type $1 \mathrm{~N}$-terminal propeptide (PINP) derives from the type 1 collagen formation process, from its precursor, procollagen [17, 39]. It is considered a standard indicator of bone formation [27]. Kučukalić-Selimović et al. analyzed the role of this BMT in the bone status assessment and found a significant negative correlation between BMD (at the femoral neck, total hip, and lumbar spine) and serum levels of PINP [40].

NTx and CTx are considered markers of bone resorption [17]. These two BMTs are two different forms of a telopeptide of type I collagen, acting in the collagen degradation process, and are found in serum and in urines [41-43]. NTx showed an association with the T-score spine and hip levels at baseline, while greater CTx values were associated with lower spine, hip, and femur BMD at baseline. Since they are markers of resorption, their levels may increase in increased bone turnover, leading to a reduction in BMD and T-score. Indeed, high bone turnover setting (hyperthyroidism, hyperparathyroidism, and Paget disease) is associated with greater values of BMTs [44-49]. This has also been reported in postmenopausal women when a reduction of BMD may be appreciable $[50,51]$. Although CTx and PINP have been recommended as the reference standard for bone resorption and bone formation [27], in the light of the results of this systematic review, all BMTs can be statistically related to specific complications.

This study showed several limitations, as data were based on a large population, hence they carry a high risk of bias. There is still little literature available about the actual therapeutic role for these BMTs. In fact, the studies analyzed in this review did not evaluate BMTs as primary outcomes. The pathophysiology of these markers and their relationship with osteoporosis complications should be analyzed more specifically, as they could have marked clinical potential. Future studies should evaluate whether osteoporosis complication can be predicted from variation of a given BMT, and, subsequently establish which drug could be suitable for a specific individual. These substances can be measured in serum or urine by immunological tests $[52,53]$, and their levels are influenced by endogenous and exogenous factors $[17,19,31,54,55]$. As differences in sampling methods still remain, specific research groups highlighted the need for standardization of the collection method [27]. Another important limitation of this review is the heterogeneity of the studies evaluated, as they analyzed the intervention of different types of drugs, or the same drugs with different dosages. Furthermore, daily vitamin D administration was not homogeneous in all studies. Finally, future studies should consider to standardize the measurement methods of BMTs.

\section{Conclusion}

The present systematic review shows that further studies should validate the use of BMTs in clinical practice. Our analysis supports the adoption of BMTs during pharmacological therapy setting of patients with postmenopausal osteoporosis. Further studies are required to analyze their role in predicting complications as a primary outcome.

\section{Abbreviations \\ SD: Standard deviation; IQR: While median and interquartile range; RCTs: Randomized clinical trials; OCEBM: Oxford Centre of Evidence-Based Medicine; BMD: Bone mineral density; BMI: Body mass index; \\ BTMs: Biochemical markers of bone turnover; bALP: Bone alkaline phosphatase; PINP: Procollagen type I N propeptide; bCTx: Serum cross- linked C-telopeptides of type I collagen; NTx: Urinary cross-linked N- telopeptides of type I collagen}

\section{Acknowledgements}

None

\section{Authors' contributions}

FM: literature search, data extraction, methodological quality assessment, statistical analyses, and writing; NM: supervision, revision, and final approval; RG: literature search, data extraction, and methodological quality assessment; FS: revision; PGM and MT: supervision. The authors read and approved the final manuscript.

\section{Funding}

No external source of funding was used. Open Access funding enabled and organized by Projekt DEAL.

\section{Availability of data and materials}

This study does not contain any third material.

\section{Declarations}

Ethics approval and consent to participate

This article does not contain any studies with human participants or animals performed by any of the authors.

Consent for publication

All the authors approved the manuscript.

\section{Competing interests}

The authors declare that they have no competing interests.

\section{Author details}

'Department of Orthopaedic Surgery, University Clinic Aachen, RWTH Aachen University Clinic, Pauwelsstraße 30, 52074 Aachen, Germany.

${ }^{2}$ Department of Medicine, Surgery and Dentistry, University of Salerno, Via S. Allende, 84081 Baronissi, SA, Italy. ${ }^{3}$ School of Pharmacy and Bioengineering, Keele University Faculty of Medicine, Thornburrow Drive, Stoke on Trent, Newcastle-under-Lyme, England. ${ }^{4}$ Queen Mary University of London, Barts and the London School of Medicine and Dentistry, Centre for Sports and Exercise Medicine, Mile End Hospital, 275 Bancroft Road, London E1 4DG, England. ${ }^{5}$ Department of Orthopedics and Trauma Surgery, Ospedale San Carlo di Potenza, Potenza, Italy. ${ }^{6}$ Department of Biomedical Sciences for Health, University of Milan, Milan, Italy. ${ }^{7}$ Department of Orthopaedic Surgery, IRCCS Istituto Ortopedico Galeazzi, Milan, Italy. 


\section{Received: 21 April 2021 Accepted: 23 May 2021} Published online: 31 May 2021

\section{References}

1. Borgstrom F, Sobocki P, Strom O, et al. The societal burden of osteoporosis in Sweden. Bone. 2007;40(6):1602-9. https://doi.org/10.1016/j.bone.2007.02. 027.

2. Burge R, Dawson-Hughes B, Solomon DH, Wong JB, King A, Tosteson A. Incidence and economic burden of osteoporosis-related fractures in the United States, 2005-2025. J Bone Miner Res. 2007;22(3):465-75. https://doi. org/10.1359/jbmr.061113.

3. Ray NF, Chan JK, Thamer M, Melton $\sqcup$ III. Medical expenditures for the treatment of osteoporotic fractures in the United States in 1995: report from the National Osteoporosis Foundation. J Bone Miner Res. 1997;12(1): 24-35. https://doi.org/10.1359/jbmr.1997.12.1.24.

4. Bennett JE, Li G, Foreman K, Best N, Kontis V, Pearson C, et al. The future of life expectancy and life expectancy inequalities in England and Wales: Bayesian spatiotemporal forecasting. Lancet. 2015;386(9989):163-70. https:// doi.org/10.1016/S0140-6736(15)60296-3.

5. Kontis V, Bennett JE, Mathers CD, Li G, Foreman K, Ezzati M. Future life expectancy in 35 industrialised countries: projections with a Bayesian model ensemble. Lancet. 2017;389(10076):1323-35. https://doi.org/10.1016/S01406736(16)32381-9.

6. Khosla S, Hofbauer LC. Osteoporosis treatment: recent developments and ongoing challenges. Lancet Diabetes Endocrinol. 2017;5(11):898-907. https://doi.org/10.1016/\$2213-8587(17)30188-2.

7. Black DM, Rosen CJ. Clinical practice. Postmenopausal osteoporosis. N Engl J Med. 2016;374(3):254-62. https://doi.org/10.1056/NEJMcp1513724.

8. Khosla S, Bilezikian JP, Dempster DW, Lewiecki EM, Miller PD, Neer RM, et al. Benefits and risks of bisphosphonate therapy for osteoporosis. J Clin Endocrinol Metab. 2012;97(7):2272-82. https://doi.org/10.1210/jc.2012-1027.

9. Brown JP, Roux C, Ho PR, Bolognese MA, Hall J, Bone HG, et al. Denosumab significantly increases bone mineral density and reduces bone turnover compared with monthly oral ibandronate and risedronate in postmenopausal women who remained at higher risk for fracture despite previous suboptimal treatment with an oral bisphosphonate. Osteoporos Int. 2014;25(7):1953-61. https://doi.org/10.1007/s00198-014-2692-7.

10. Chung YS, Lim SK, Chung HY, Lee IK, Park IH, Kim GS, et al. Comparison of monthly ibandronate versus weekly risedronate in preference, convenience, and bone turnover markers in Korean postmenopausal osteoporotic women. Calcif Tissue Int. 2009;85(5):389-97. https://doi.org/10.1007/s00223009-9294-y.

11. Guanabens N, Monegal A, Cerda D, et al. Randomized trial comparing monthly ibandronate and weekly alendronate for osteoporosis in patients with primary biliary cirrhosis. Hepatology. 2013;58(6):2070-8. https://doi. org/10.1002/hep.26466.

12. Retraction: Paper "Comparison of effects of alendronate and raloxifene on lumbar bone mineral density, bone turnover, and lipid metabolism in elderly women with osteoporosis" by Iwamoto J, et al. [Yonsei Med J 2008; 49(1):119-128]. Yonsei Med J. 2018;59:167.

13. Leder BZ, Tsai JN, Uihlein AV, Wallace PM, Lee $H$, Neer RM, et al. Denosumab and teriparatide transitions in postmenopausal osteoporosis (the DATA-Switch study): extension of a randomised controlled trial. Lancet. 2015;386(9999):1147-55. https://doi.org/10.1016/S0140-6736(15)61120-5.

14. Miller PD, Pannacciulli N, Brown JP, Czerwinski E, Nedergaard BS, Bolognese MA, et al. Denosumab or zoledronic acid in postmenopausal women with osteoporosis previously treated with oral bisphosphonates. J Clin Endocrinol Metab. 2016;101(8):3163-70. https://doi.org/10.1210/jc.2016-1801.

15. Srivastava $M$, Deal C. Osteoporosis in elderly: prevention and treatment. Clin Geriatr Med. 2002;18(3):529-55. https://doi.org/10.1016/S0749-0690(02 )00022-8.

16. Ettinger MP. Aging bone and osteoporosis: strategies for preventing fractures in the elderly. Arch Intern Med. 2003;163(18):2237-46. https://doi. org/10.1001/archinte.163.18.2237.

17. Hlaing TT, Compston JE. Biochemical markers of bone turnover - uses and limitations. Ann Clin Biochem. 2014;51(2):189-202. https://doi.org/10.1177/ 0004563213515190.

18. Jain S, Camacho P. Use of bone turnover markers in the management of osteoporosis. Curr Opin Endocrinol Diabetes Obes. 2018;25(6):366-72. https://doi.org/10.1097/MED.0000000000000446.
19. Eastell R, Pigott T, Gossiel F, Naylor KE, Walsh JS, Peel NFA. Diagnosis of endocrine disease: bone turnover markers: are they clinically useful? Eur J Endocrinol. 2018;178(1):R19-31. https://doi.org/10.1530/EJE-17-0585.

20. Christenson RH. Biochemical markers of bone metabolism: an overview. Clin Biochem. 1997;30(8):573-93. https://doi.org/10.1016/S0009-9120(97)00113-6.

21. Bauer DC, Garnero P, Harrison SL, Cauley JA, Eastell R, Ensrud KE, et al. Biochemical markers of bone turnover, hip bone loss, and fracture in older men: the MrOS study. J Bone Miner Res. 2009;24(12):2032-8. https://doi. org/10.1359/jbmr.090526.

22. Eastell R, Szulc P. Use of bone turnover markers in postmenopausal osteoporosis. Lancet Diabetes Endocrinol. 2017;5(11):908-23. https://doi. org/10.1016/\$2213-8587(17)30184-5.

23. Bell KJ, Hayen A, Irwig $L$, et al. The potential value of monitoring bone turnover markers among women on alendronate. J Bone Miner Res. 2012; 27(1):195-201. https://doi.org/10.1002/jbmr.525.

24. Lorentzon M, Branco J, Brandi ML, Bruyère O, Chapurlat R, Cooper C, et al. Algorithm for the use of biochemical markers of bone turnover in the diagnosis, assessment and follow-up of treatment for osteoporosis. Adv Ther. 2019;36(10):2811-24. https://doi.org/10.1007/s12325-019-01063-9.

25. Moher D, Liberati A, Tetzlaff J, Altman DG, for the PRISMA Group. Preferred reporting items for systematic reviews and meta-analyses: the PRISMA statement. BMJ. 2009;339(jul21 1):b2535. https://doi.org/10.1136/bmj.b2535.

26. Howick J Cl, Glasziou P, Greenhalgh T, Carl Heneghan, Liberati A, Moschetti I, Phillips B, Thornton H, Goddard O, Hodgkinson M. 2011. The 2011 Oxford CEBM levels of evidence. Oxford Centre for Evidence-Based Medicine Available at https://www.cebmnet/indexaspx?o=5653.

27. Vasikaran S, Eastell R, Bruyere $\mathrm{O}$, et al. Markers of bone turnover for the prediction of fracture risk and monitoring of osteoporosis treatment: a need for international reference standards. Osteoporos Int. 2011;22(2):391-420. https://doi.org/10.1007/s00198-010-1501-1.

28. Hill PA. Bone remodelling. Br J Orthod. 1998;25(2):101-7. https://doi.org/10.1 093/ortho/25.2.101.

29. Florencio-Silva R, Sasso GR, Sasso-Cerri E, et al. Biology of bone tissue: structure, function, and factors that influence bone cells. Biomed Res Int. 2015;2015:421746

30. Biver E. Use of bone turnover markers in clinical practice. Curr Opin Endocrinol Diabetes Obes. 2012;19(6):468-73. https://doi.org/10.1097/MED. 0b013e3283591492.

31. Civitelli R, Armamento-Villareal R, Napoli N. Bone turnover markers: understanding their value in clinical trials and clinical practice. Osteoporos Int. 2009;20(6):843-51. https://doi.org/10.1007/s00198-009-0838-9.

32. Greenblatt MB, Tsai JN, Wein MN. Bone turnover markers in the diagnosis and monitoring of metabolic bone disease. Clin Chem. 2017;63(2):464-74. https://doi.org/10.1373/clinchem.2016.259085.

33. Parfitt AM, Drezner MK, Glorieux FH, Kanis JA, Malluche H, Meunier PJ, et al. Bone histomorphometry: standardization of nomenclature, symbols, and units. Report of the ASBMR Histomorphometry Nomenclature Committee J Bone Miner Res. 1987;2(6):595-610. https://doi.org/10.1002/jbmr.5650020617.

34. Bjarnason NH, Sarkar S, Duong T, Mitlak B, Delmas PD, Christiansen C. Six and twelve month changes in bone turnover are related to reduction in vertebral fracture risk during 3 years of raloxifene treatment in postmenopausal osteoporosis. Osteoporos Int. 2001;12(11):922-30. https:// doi.org/10.1007/s001980170020.

35. Dai Z, Wang R, Ang LW, Yuan JM, Koh WP. Bone turnover biomarkers and risk of osteoporotic hip fracture in an Asian population. Bone. 2016:83:1717. https://doi.org/10.1016/j.bone.2015.11.005.

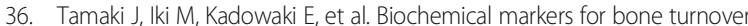
predict risk of vertebral fractures in postmenopausal women over 10 years: the Japanese Population-based Osteoporosis (JPOS) Cohort Study. Osteoporos Int. 2013;24(3):887-97. https://doi.org/10.1007/s00198-012-2106-7.

37. Chen H, Li J, Wang Q. Associations between bone-alkaline phosphatase and bone mineral density in adults with and without diabetes. Medicine (Baltimore). 2018;97(17):e0432. https://doi.org/10.1097/MD.000000000001 0432.

38. Lumachi F, Orlando R, Fallo F, Basso SM. Relationship between bone formation markers bone alkaline phosphatase, osteocalcin and aminoterminal propeptide of type I collagen and bone mineral density in elderly men. Preliminary results. In Vivo. 2012;26(6):1041-4.

39. Simon LS, Krane SM, Wortman PD, et al. Serum levels of type I and III procollagen fragments in Paget's disease of bone. J Clin Endocrinol Metab. 1984;58(1):110-20. https://doi.org/10.1210/jcem-58-1-110. 
40. Kučukalić-Selimović E, Valjevac A, Hadzovic-Dzuvo A. The utility of procollagen type $1 \mathrm{~N}$-terminal propeptide for the bone status assessment in postmenopausal women. Bosn J Basic Med Sci. 2013;13(4):259-65. https:// doi.org/10.17305/bjbms.2013.2337.

41. Garnero P, Cloos P, Sornay-Rendu E, Qvist P, Delmas PD. Type I collagen racemization and isomerization and the risk of fracture in postmenopausal women: the OFELY prospective study. J Bone Miner Res. 2002;17(5):826-33. https://doi.org/10.1359/jbmr.2002.17.5.826.

42. Garnero P, Buchs N, Zekri J, Rizzoli R, Coleman RE, Delmas PD. Markers of bone turnover for the management of patients with bone metastases from prostate cancer. Br J Cancer. 2000;82(4):858-64. https://doi.org/10.1054/ bjoc.1999.1012.

43. Christgau S. Circadian variation in serum CrossLaps concentration is reduced in fasting individuals. Clin Chem. 2000;46(3):431. https://doi.org/10.1 093/clinchem/46.3.431a.

44. Garnero P, Gineyts E, Riou JP, et al. Assessment of bone resorption with a new marker of collagen degradation in patients with metabolic bone disease. J Clin Endocrinol Metab. 1994;79:780-5.

45. Delmas PD. Biochemical markers of bone turnover in Paget's disease of bone. J Bone Miner Res. 1999;14(Suppl 2):66-9. https://doi.org/10.1002/jbmr. 5650140213

46. Ohishi T, Takahashi M, Kushida K, Horiuchi K, Ishigaki S, Inoue T. Quantitative analyses of urinary pyridinoline and deoxypyridinoline excretion in patients with hyperthyroidism. Endocr Res. 1992;18(4):281-90. https://doi.org/10.1 080/07435809209111037.

47. Takami H, Ikeda Y, Hayashi K, Hayashi M, Konishi K, Saruta T, et al. Clinical assessment of collagen cross-linked N-telopeptides as a marker of bone metabolism in patients with primary hyperparathyroidism. Biomed Pharmacother. 1999;53(7):329-33. https://doi.org/10.1016/S0753-3322 (00)88506-6.

48. Seibel MJ, Gartenberg F, Silverberg SJ, Ratcliffe A, Robins SP, Bilezikian JP. Urinary hydroxypyridinium cross-links of collagen in primary hyperparathyroidism. J Clin Endocrinol Metab. 1992;74(3):481-6. https://doi. org/10.1210/jcem.74.3.1740480.

49. Randall AG, Kent GN, Garcia-Webb P, Bhagat Cl, Pearce DJ, Gutteridge DH, et al. Comparison of biochemical markers of bone turnover in Paget disease treated with pamidronate and a proposed model for the relationships between measurements of the different forms of pyridinoline cross-links. J Bone Miner Res. 1996;11(8):1176-84. https://doi.org/10.1002/jbmr.565011081 7.

50. Hassager C, Colwell A, Assiri AM, et al. Effect of menopause and hormone replacement therapy on urinary excretion of pyridinium cross-links: a longitudinal and cross-sectional study. Clin Endocrinol. 1992;37(1):45-50. https://doi.org/10.1111/j.1365-2265.1992.tb02282.x.

51. Gurban CV, Balas MO, Vlad MM, et al. Bone turnover markers in postmenopausal osteoporosis and their correlation with bone mineral density and menopause duration. Romanian J Morphol Embryol. 2019;60(4): 1127-35.

52. Hanson DA, Weis MA, Bollen AM, Maslan SL, Singer FR, Eyre DR. A specific immunoassay for monitoring human bone resorption: quantitation of type I collagen cross-linked N-telopeptides in urine. J Bone Miner Res. 1992;7(11): 1251-8. https://doi.org/10.1002/jbmr.5650071119.

53. Glover SJ, Gall M, Schoenborn-Kellenberger O, Wagener M, Garnero P, Boonen $\mathrm{S}$, et al. Establishing a reference interval for bone turnover markers in 637 healthy, young, premenopausal women from the United Kingdom, France, Belgium, and the United States. J Bone Miner Res. 2009;24(3):38997. https://doi.org/10.1359/jbmr.080703.

54. Pratt JH, Manatunga AK, Peacock M. A comparison of the urinary excretion of bone resorptive products in white and black children. J Lab Clin Med. 1996;127(1):67-70. https://doi.org/10.1016/S0022-2143(96)90167-5.

55. Mora S, Prinster C, Proverbio MC, Bellini A, de Poli SCL, Weber G, et al. Urinary markers of bone turnover in healthy children and adolescents: agerelated changes and effect of puberty. Calcif Tissue Int. 1998;63(5):369-74. https://doi.org/10.1007/s002239900542.

56. Anastasilakis AD, Polyzos SA, Gkiomisi A, Saridakis ZG, Digkas D, Bisbinas I, et al. Denosumab versus zoledronic acid in patients previously treated with zoledronic acid. Osteoporos Int. 2015;26(10):2521-7. https://doi.org/10.1007/ s00198-015-3174-2.

57. Black DM, Schwartz AV, Ensrud KE, Cauley JA, Levis S, Quandt SA, et al. Effects of continuing or stopping alendronate after 5 years of treatment: the
Fracture Intervention Trial Long-term Extension (FLEX): a randomized trial. JAMA. 2006:296(24):2927-38. https://doi.org/10.1001/jama.296.24.2927.

58. Black DM, Reid IR, Cauley JA, Cosman F, Leung PC, Lakatos P, et al. The effect of 6 versus 9 years of zoledronic acid treatment in osteoporosis: a randomized second extension to the HORIZON-Pivotal Fracture Trial (PFT). J Bone Miner Res. 2015;30(5):934-44. https://doi.org/10.1002/jbmr.2442.

59. Chesnut $\mathrm{CH}$ 3rd, Skag A, Christiansen C, et al. Effects of oral ibandronate administered daily or intermittently on fracture risk in postmenopausal osteoporosis. J Bone Miner Res. 2004;19(8):1241-9. https://doi.org/10.1359/ JBMR.040325.

60. Cosman F, Eriksen EF, Recknor C, Miller PD, Guañabens N, Kasperk C, et al. Effects of intravenous zoledronic acid plus subcutaneous teriparatide [rhPTH(1-34)] in postmenopausal osteoporosis. J Bone Miner Res. 2011;26(3): 503-11. https://doi.org/10.1002/jbmr.238.

61. Cosman F, Crittenden DB, Adachi JD, Binkley N, Czerwinski E, Ferrari S, et al. Romosozumab treatment in postmenopausal women with osteoporosis. N Engl J Med. 2016;375(16):1532-43. https://doi.org/10.1056/NEJMoa1607948.

62. Gonnelli S, Caffarelli C, Tanzilli L, Pondrelli C, Lucani B, Franci BM, et al. Effects of intravenous zoledronate and ibandronate on carotid intima-media thickness, lipids and FGF-23 in postmenopausal osteoporotic women. Bone. 2014;61:27-32. https://doi.org/10.1016/j.bone.2013.12.017.

63. Greenspan SL, Perera S, Ferchak MA, Nace DA, Resnick NM. Efficacy and safety of single-dose zoledronic acid for osteoporosis in frail elderly women: a randomized clinical trial. JAMA Intern Med. 2015;175(6):913-21. https://doi. org/10.1001/jamainternmed.2015.0747.

64. Grey A, Bolland MJ, Wattie D, Horne A, Gamble G, Reid IR. The antiresorptive effects of a single dose of zoledronate persist for two years: a randomized, placebo-controlled trial in osteopenic postmenopausal women. J Clin Endocrinol Metab. 2009;94(2):538-44. https://doi.org/10.1210/jc.2008-2241.

65. Grey A, Bolland M, Wong S, Horne A, Gamble G, Reid IR. Low-dose zoledronate in osteopenic postmenopausal women: a randomized controlled trial. J Clin Endocrinol Metab. 2012;97(1):286-92. https://doi.org/1 0.1210/jc.2011-2081.

66. Hooper MJ, Ebeling PR, Roberts AP, Graham JJ, Nicholson GC, D'Emden M, et al. Risedronate prevents bone loss in early postmenopausal women: a prospective randomized, placebo-controlled trial. Climacteric. 2005:8(3):25162. https://doi.org/10.1080/13697130500118126.

67. Kendler DL, Bone HG, Massari F, Gielen E, Palacios S, Maddox J, et al. Bone mineral density gains with a second 12-month course of romosozumab therapy following placebo or denosumab. Osteoporos Int. 2019;30(12): 2437-48. https://doi.org/10.1007/s00198-019-05146-9.

68. Iwamoto J, Sato Y, Uzawa M, Takeda T, Matsumoto H. Comparison of effects of alendronate and raloxifene on lumbar bone mineral density, bone turnover, and lipid metabolism in elderly women with osteoporosis. Yonsei Med J. 2008;49(1):119-28. https://doi.org/10.3349/ymj.2008.49.1.119.

69. Iwamoto J, Makita K, Sato Y, Takeda T, Matsumoto H. Alendronate is more effective than elcatonin in improving pain and quality of life in postmenopausal women with osteoporosis. Osteoporos Int. 2011;22(10): 2735-42. https://doi.org/10.1007/s00198-010-1495-8.

70. Leder BZ, Tsai JN, Uihlein AV, Burnett-Bowie SAM, Zhu Y, Foley K, et al. Two years of denosumab and teriparatide administration in postmenopausal women with osteoporosis (The DATA Extension Study): a randomized controlled trial. J Clin Endocrinol Metab. 2014;99(5):1694-700. https://doi. org/10.1210/jc.2013-4440.

71. Liang BC, Shi ZY, Wang B, Wu P, Kong LC, Yao JL, et al. Intravenous zoledronic acid $5 \mathrm{mg}$ on bone turnover markers and bone mineral density in East China subjects with newly diagnosed osteoporosis: a 24-month clinical study. Orthop Surg. 2017:9(1):103-9. https://doi.org/10.1111/os.123 07.

72. Lufkin EG, Whitaker MD, Nickelsen T, Argueta R, Caplan RH, Knickerbocker RK, et al. Treatment of established postmenopausal osteoporosis with raloxifene: a randomized trial. J Bone Miner Res. 1998;13(11):1747-54. https://doi.org/10.1359/jbmr.1998.13.11.1747.

73. McClung MR, Grauer A, Boonen S, et al. Romosozumab in postmenopausal women with low bone mineral density. N Engl J Med. 2014;370(5):412-20. https://doi.org/10.1056/NEJMoa1305224.

74. McClung M, Miller P, Recknor C, Mesenbrink P, Bucci-Rechtweg C, Benhamou CL. Zoledronic acid for the prevention of bone loss in postmenopausal women with low bone mass: a randomized controlled trial. Obstet Gynecol. 2009;114(5):999-1007. https://doi.org/10.1097/AOG. Ob013e3181bdce0a. 
75. McClung MR, Brown JP, Diez-Perez A, et al. Effects of 24 months of treatment with romosozumab followed by 12 months of denosumab or placebo in postmenopausal women with low bone mineral density: a randomized, double-blind, phase 2, parallel group study. J Bone Miner Res. 2018;33(8):1397-406. https://doi.org/10.1002/jbmr.3452.

76. Meunier PJ, Roux C, Seeman E, Ortolani S, Badurski JE, Spector TD, et al. The effects of strontium ranelate on the risk of vertebral fracture in women with postmenopausal osteoporosis. N Engl J Med. 2004;350(5):459-68. https://doi. org/10.1056/NEJMoa022436.

77. Meunier PJ, Roux C, Ortolani S, Diaz-Curiel M, Compston J, Marquis P, et al. Effects of long-term strontium ranelate treatment on vertebral fracture risk in postmenopausal women with osteoporosis. Osteoporos Int. 2009;20(10): 1663-73. https://doi.org/10.1007/s00198-008-0825-6.

78. Morii H, Ohashi Y, Taketani Y, Fukunaga M, Nakamura T, Itabashi A, et al. Effect of raloxifene on bone mineral density and biochemical markers of bone turnover in Japanese postmenopausal women with osteoporosis: results from a randomized placebo-controlled trial. Osteoporos Int. 2003: 14(10):793-800. https://doi.org/10.1007/s00198-003-1424-1.

79. Paggiosi MA, Peel N, McCloskey E, Walsh JS, Eastell R. Comparison of the effects of three oral bisphosphonate therapies on the peripheral skeleton in postmenopausal osteoporosis: the TRIO study. Osteoporos Int. 2014;25(12): 2729-41. https://doi.org/10.1007/s00198-014-2817-z.

80. Papapoulos S, Chapurlat R, Libanati C, Brandi ML, Brown JP, Czerwiński E, et al. Five years of denosumab exposure in women with postmenopausal osteoporosis: results from the first two years of the FREEDOM extension. J Bone Miner Res. 2012;27(3):694-701. https://doi.org/10.1002/jbmr.1479.

81. Recknor C, Czerwinski E, Bone HG, Bonnick SL, Binkley N, Palacios S, et al. Denosumab compared with ibandronate in postmenopausal women previously treated with bisphosphonate therapy: a randomized open-label trial. Obstet Gynecol. 2013;121(6):1291-9. https://doi.org/10.1097/AOG.0b013 e318291718c

82. Saag KG, Petersen J, Brandi ML, Karaplis AC, Lorentzon M, Thomas T, et al. Romosozumab or alendronate for fracture prevention in women with osteoporosis. N Engl J Med. 2017;377(15):1417-27. https://doi.org/10.1056/ NEJMoa1708322

83. Sanad Z, Ellakwa H, Desouky B. Comparison of alendronate and raloxifene in postmenopausal women with osteoporosis. Climacteric. 2011;14(3):369-77. https://doi.org/10.3109/13697137.2010.537408.

84. Tsai JN, Uihlein AV, Lee H, Kumbhani R, Siwila-Sackman E, McKay EA, et al. Teriparatide and denosumab, alone or combined, in women with postmenopausal osteoporosis: the DATA study randomised trial. Lancet. 2013;382(9886):50-6. https://doi.org/10.1016/50140-6736(13)60856-9.

85. Tsai JN, Lee H, David NL, Eastell R, Leder BZ. Combination denosumab and high dose teriparatide for postmenopausal osteoporosis (DATA-HD): a randomised, controlled phase 4 trial. Lancet Diabetes Endocrinol. 2019;7(10): 767-75. https://doi.org/10.1016/S2213-8587(19)30255-4.

\section{Publisher's Note}

Springer Nature remains neutral with regard to jurisdictional claims in published maps and institutional affiliations.

Ready to submit your research? Choose BMC and benefit from:

- fast, convenient online submission

- thorough peer review by experienced researchers in your field

- rapid publication on acceptance

- support for research data, including large and complex data types

- gold Open Access which fosters wider collaboration and increased citations

- maximum visibility for your research: over $100 \mathrm{M}$ website views per year

At BMC, research is always in progress.

Learn more biomedcentral.com/submissions 